\title{
REMEDIES FOR RHUS DERMATITIS
}

\author{
JAMES B. MCNAIR \\ WASHINGTON, D. C.
}

Practical therapeutics may be deductive or inductive; may, that is to say, be based on some general principles which in their turn depend on the conceptions held as to disease processes and the pharmacodynamics of certain substances; or they may be merely the result of more or less discrete observations as to the curative value of such substances in certain diseased conditions. The former method in therapeutics is often spoken of as rational, and the latter as empiric.

\section{EMPIRIC REMEDIES}

In the list of remedies for rhus dermatitis of the empiric type, we may include all those remedies that do not take into account the chemical composition of the poison. Horsfield, ${ }^{1} 1798$, before anything regarding the chemical nature of the poison was known, listed these remedies: ashes of the leaves and wood of the poisonous rhus, soot dissolved in milk, an aqueous solution of sodium chlorid, copper sulphate, or ammonium chlorid, leaves of Datura stramonium, juice of Sanguinaria canadensis, unguentum simplex, sweet oil, and emollient cataplasms, and an ointment of 1 dram of saccharum saturni with 1 ounce of unguentum simplex. Christy ${ }^{2}$ (1829) recommended topical applications of solutions of either lead acetate, ammonium chlorid or an infusion of digitalis. He advocated producing blisters above inflamed parts. He recommended solidago canadensis, an Indian remedy, and said its roots were chewed and part of the resultant saliva swallowed and part rubbed on the inflamed area. Dakin, ${ }^{3}$ writing also in 1829 , used locally in the treatment of this disease this prescription:

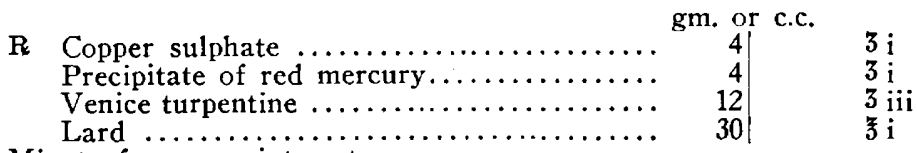

Mix to form an ointment.

1. Horsfield, Thomas: An Experimental Dissertation on the Rhus Vernix, R. Radicans and R. Glabrum, Inaugural Dissertation for the Degree of M.D. at the University of Pennsylvania, 1798. Also in Medical Theses of University of Pennsylvania by Charles Caldwell 1:117-163, 1805.

2. Christy, A.: An Essay on the Poisonous Qualities of Some Species of the Genius Rhus of Linneaus, New York Med. and Phys. J., N. S. 1:21-30, 1829.

3. Dakin, R.: Remarks on the Cutaneous Affection Produced by Certain Poisonous Vegetables, Am. J. M. Sc. 4:98-100, 1829. 
In 1836, Pickett ${ }^{4}$ records the local application of an old Massachusetts Indian remedy of an infusion of the bruised leaves and twigs of Diervilla canadensis (bush honeysuckle).

In 1837 , an anonymous article ${ }^{5}$ appeared, in which the treatment recommended for rhus poisoning included a topical application of from 20 to 40 grains of silver, nitrate to 1 ounce of water, the skin having previously been washed clean with warm water and soap. A topical application of from 10 to 20 grains of mercuric chlorid to 1 ounce of water is not considered so good as the silver nitrate. Remedies which are considered as of little or no value, whether in weak or strong solution, are: Diervilla canadensis, Prot. lead acetate, potassium nitrate, potassium carbonate and sodium chlorid.

Smith, ${ }^{6}$ in 1851 , was led to use tincture of iodin in rhus poisoning, as it had been considered beneficial in the treatment of venomous reptile bites.

In 1858 , Dr. Joseph Khittel ${ }^{7}$ announced that the poison of rhus toxicodendron is a volatile alkaloid. Seven years later, in 1865 , Maisch ${ }^{8}$ in contrast to Khittel, considered the poison a volatile organic acid, which he named toxicodendric acid. These investigations had a noticeable effect on the rational treatment of the disease; but they are cited here merely to show that old remedies continued to be used and new ones were recommended, which did not take into consideration the volatile alkaloid of Khittel nor the volatile acid of Maisch.

In 1867 , Canfield ${ }^{9}$ described the mode of using Grindelia robusta and $G$. hirsutula as antidotes for poison oak. Either the bruised fresh herb was rubbed on the affected parts or a strong decoction, made by boiling either the fresh or dried herb, was used to wash the poisoned surfaces.

Risk $^{10}$ (1871) recommended the local application of a decoction of white oak. He also cites the alum solution of Hopkins, Dunn's decoction of cottonwood.leaves for internal use, and the following formulas of Bailey:

4. Pickett, N. B.: Diervilla Canadensis, Boston M. \& S. J. 15:380, 1836-1837.

5. Erythema Venenosa, Boston M. \& S. J. 17:347-350, 1837-1838.

6. Smith, T.: Observations on the Treatment of External Poisoning by Vegetable Substances, West. Lancet 12:293-295, 1851.

7. Khittel. Joseph: Wittstein's Vierteljahresschrift f. praktische pharmacie. $7: 348,1858$.

8. Maisch, J. M.: On the Active Principle of Rhus Toxicodendron, Am. J. Pharm. 38:4-12, 1865.

9. Canfield, C. A.: Grindelia as an Antidote to Poison Oak, Pacific M. \& S. J. 9:294-298, 1867.

10. Risk, J. B. A.: Poison Oak, Cincin. M. Repertory 4:316-318, 1871. 
gm. or c.c.

R Mercuric chlorid ....................... $z_{\text {ss }}$

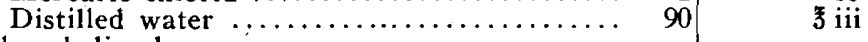

Add and dissolve

Ammonium chlorid $\ldots \ldots \ldots \ldots \ldots \ldots \ldots \ldots, 4, \quad 3 i$

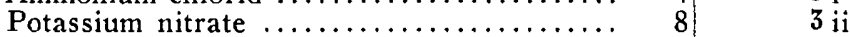

Sig.: Apply thoroughly three times a day.

Dr. James C. White ${ }^{11}$ sums up the empiric treatment of the inflammation up to 1873 thus:

A great many remedies have been recommended, in both medical and botanial books, for the treatment of persons poisoned by rhus, while others of a "domestic" character are used in various parts of the country. Among the former, a solution of acetate of lead holds the most conspicuous place. Torrey, in his "Botany of New York," says one of the best applications is a solution of sugar of lead, after the use of saline cathartics. Dr. Bigelow ${ }^{12}$ thinks the application of acetate of lead as useful as any external palliative, and that it should be used as cold as possible. Solutions of sulphate of copper and of other metallic salts have also been recommended by physicians. Among the domestic remedies, vinegar, and solutions of saleratus and carbonate of soda, are widely and highly esteemed. A decoction of Virginia snakeroot (serpentaria) is also supposed to possess special power over the poison. In an old copy of Bigelow's "Florula Bostoniensis," picked up in a second-hand bookstore, I find, in connection with Rhus toxicodendron, a marginal note by its former owners, stating that, if soft-soap be rubbed thoroughly into the hands after handling specimens, its poisonous action will be prevented. The list comprises most of the other articles recommended by writers in medical journals as "cures" for rhus poisoning, many of which are stated to be "specific," and to act "like magic." It is needless to give the detailed directions for their application: Grindelia robusta, Comptonia asplenifolia, dulcamara berries (in cream), Cephalanthus occidentalis, Gelsemium sempervirens, rhamnus, Lactuca elongata, Collinsonia canadensis, Quercus alba (bark), Lindera benzoin, Sassafras officinale, Atropa belladonna, solutions of bromin, sulphate of zinc, chlorate of potash, chlorinated soda, sulphite of sodium, alum curd, and Turkish bath.

It is always a suspicious element in therapeutics when remedies are recommended as specifics, and when the list of cures for any one disease is exceptionally long. It is not strange, therefore, that we find even nonprofessional writers remarking that "the reputed remedies are more numerous than efficacious (Torrey and Gray)."

De Witt, ${ }^{13} 1874$, used the following prescription locally:

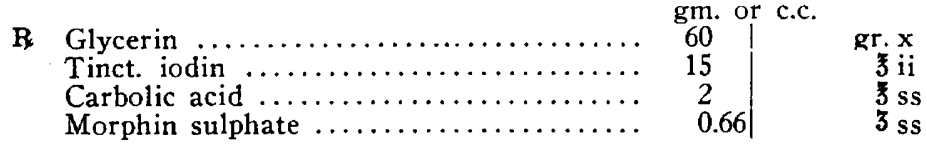

11. White, J. C.: On the Action of Rhus Venenata and Rhus Toxicodendron on the Human Skin, New York M. J. 17:225-249, 1873.

12. Bigelow, J.: Am. Medical Botany 1:96; 3:20, 1817-1820.

13. De Witt, W. H.: Poisoning by Rhus Toxicodendron, Am. J. M. Sc. N. S. 67: 116-118, 1874. 
Humphrey ${ }^{14}$ in the same year recommended sponging the surface every hour with one part of zinc sulphate in twenty-four parts of water.

Morrison, ${ }^{15} 1874$, published the following formula to be applied constantly to the affected parts :

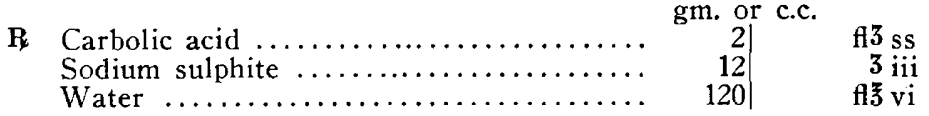

He said that he did not know that the sodium sulphite was of any use in the formula; but he knew that it would not be of much use without the phenol (carbolic acid).

An anonymous contributor ${ }^{16}$ printed, in 1875, a prescription of mercuric chlorid, 10 grains, and lime water, 5 ounces, to be used locally. This he preferred to: sodium chlorid and potassium bicarbonate, lead acetate, lead paint thinned with linseed oil, gunpowder and water, ammonia water and olive oil.

In 1876 , Yandell ${ }^{17}$ recommended a dram of quinin in twelve pills, one-third to be taken each afternoon, with no local treatment. Of external applications, he considered mercuric chlorid the best.

In 1876 , Bernard ${ }^{18}$ used the fluid extract of Gelseminum sempervirens, externally, with good results.

Brown, ${ }^{19}$ in 1878 , stated that bromin was a cure for rhus poisoning when applied externally as a mixture of from 10 to 20 drops of bromin to an ounce of olive oil, petrolatum or glycerin. This was to be rubbed gently on the affected parts, three or four times a day, and especially on going to bed at night. The oil was washed off twice daily with castile soap.

The year 1879 was a popular year for rhus remedies; at least seven were published. Those authors that did not state the chemical nature of the poison were Kahler, ${ }^{20}$ Osborn ${ }^{21}$ and Smythe. ${ }^{22}$ Kahler used for

14. Humphrey, C. H.: Sulphate of Zinc in the Treatment of Poisoning by Rhus Radicans, Am. J. M. Sc. 68:160, 1874.

15. Morrison, S. W.: Poisoning by Rhus Radicans, Phila. M. Times 5:629, 1874-1875.

16. Poisoning by Rhus Toxicodendron, Med. and Surg. Reporter 33:306, 1875.

17. Yandell, L. P.: Poison Oak Eruption, Louisville Med. News 2:32, 1876.

18. Bernard, E. H.: Poison Oak Eruption, Louisville Med. News 2:91, 1876. Sumach, Med. Rec. 13:320, 1878.

19. Brown, S. A.: A Remedy for the Eruption of Poison Oak, Ivy and Sumach, Med. Rec. 13:320, 1878.

20. Kahler, R.: Poisoning by Rhus (Tinct. Lobelia an Antidote), Med. Brief $7: 22,1879$. 1879.

21. Osborn, T. C.: On Poison Vine Eruption, Am. M. Bi-Weekly 10:49-50,

22. Smythe, A. G.: Rhus Poisoning, Med. Rec. 16:284, 1879; Arch. Dermat. 4:320, 1879 . 
local application a mixture of ammonia water, 1 dram and tincture of lobelia, 7 drams, every two or three hours. Osborn used locally a cloth saturated with lime water overnight, to be exchanged the next morning for a bandage saturated with oak bark decoction. Smythe applied to the affected parts soft cloths, kept wet with a saturated solution of sodium thiosulphate.

Within the decade between 1880 and 1890, published remedies and "specifics" became more numerous. Blackwood ${ }^{23}$ (1880) secured no real benefit by the use of alkalies (ammonia, sodium and potassium), the sulphites and bisulphites, solutions of bromin, iodin, phenol, potassium permanganate, saturated infusions and tinctures of serpentaria and lobelia, stale beer and milk. The use of lime water he considered the best local treatment. Burgess ${ }^{24}$ (1880) recommended the local application of a solution of lead acetate ( 2 drams to a pint of water) on lint covered with oiled silk. Hardaway, ${ }^{25}$ in 1881 , specified a formula of $1 / 2$ ounce of zinc sulphate in one pint of water for local use. In 1882, Edson, ${ }^{26}$ having used gelsemium for some years with much satisfaction in pruritic troubles, believed that it might at least alleviate the pain in rhus dermatitis. He used the following formula which speedily stopped the pain:

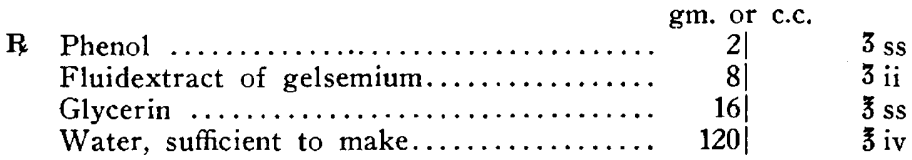

Kunze $^{27}$ (1883) recommended local treatment with lactic acid, acetic acid or salt water and lime juice. The lactic acid idea was the result of the buttermilk remedy, the acetic acid came from Central and South America and salt water and lime juice are popular remedies for manchineel poisoning. Hinton ${ }^{28}$ (1883) stated recovery follows within twenty-four hours if a strong infusion of red sassafras root is applied frequency. Leonard ${ }^{29}$ (1884) gave the following list of four topical remedies :

23. Blackwood, W. R. D.: Some Thoughts on Rhus Poisoning, Phila. Med. Times 10:618-619, 1880.

24. Burgess, T. J. W.: On the Beneficent and Toxical Effects of the Various Species of Rhus, Canad. J. M. Sc. 5:327-334, 1880.

25. Hardaway, W. A.: Rhus Poisoning, St. Louis Cour. Med. 6:401-402, 1881.

26. Edson, B.: Gelsemium in Rhus Poisoning, Med. Rec. 22:121-122, 1882.

27. Kunze, R. E.: Poison Rhus, Med. Tribune 5:111-120, 1883.

28. Hinton: Sassafras in Rhus Poisoning, Chicago Med. Rev. 7:15, 1883.

29. Leonard, W. W.: Rhus Poisoning, Med. Chron. 3:21-22, 1884-1885. 
R Tinct. lobelia

Sodium bicarbonate $\ldots \ldots \ldots \ldots \ldots \ldots \ldots \ldots$

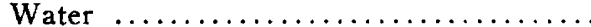

$\mathbf{R}$

Sodium thiosulphate $\ldots \ldots \ldots \ldots \ldots \ldots \ldots$

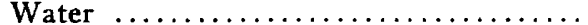

P. Spirit of nitrous ether applied without dilution several times a day.

B Bromin

Olive oil $\ldots \ldots \ldots \ldots \ldots \ldots \ldots \ldots \ldots \ldots \ldots \ldots$

\begin{tabular}{|c|c|}
\hline $\begin{array}{r}\text { gm. or } \\
60 \\
4 \\
60 \\
30 \\
500\end{array}$ & $\begin{array}{c}\text { c.c. } \\
.\end{array}$ \\
\hline $\begin{array}{r}2-4 \\
30\end{array}$ & \\
\hline
\end{tabular}

Tate $^{30}$ (1885) recommended the application of copper sulphate, 2 drams in water, 8 ounces, to stop the pain and burning.

At least seven remedies were published by different authors in 1886 . Of these, an anonymous author ${ }^{31}$ recommended an infusion of sweet fern (Comtonia asplenifolia) to be applied locally. Barnes ${ }^{32}$ recommended this compound to be taken internally:

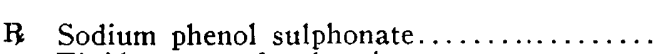
Fluidextract of gelsemium................

Water, sufficient to make................

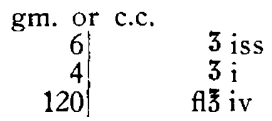

Sig.: One teaspoonful every two hours.

Brown ${ }^{33}$ published this modification of his 1878 remedy:

R. Bromin

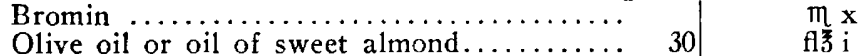
gm. or c.c.

L. D. $M \cdot^{33^{n}}$ gave as a remedy the following:

$\mathbf{R}$ Pulverized borax $\ldots \ldots \ldots \ldots \ldots \ldots \ldots \ldots \ldots \ldots \ldots \ldots \ldots \ldots \ldots \ldots \ldots \ldots$

Phenol .................................. $\mathbf{3}_{\mathrm{i}}$

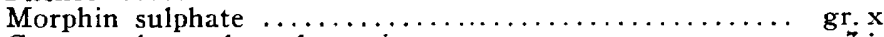

Compound powder of acacia .................. 3 iv

Water, sufficient to make...................

In criticism of this mixture, he stated that phenol and borax "help to kill the poison," and the gum acacia helps to allay irritation and pruritus. Regensburger ${ }^{34}$ recommended Russian baths in the treatment of Rhus diversiloba dermatitis.

In 1887, Baldwin ${ }^{35}$ announced a remedy in phenol ointment U. S. P., and recommended as local California remedies an infusion of Grindelia robusta, bay berry bush, eucalyptus, and buckeye. Couch ${ }^{36}$ in the same

30. Tate, W. H.: Cutaneous Poisoning with Rhus Toxicodendron, Peoria M. Month. 6:198, 1885-1886.

31. Jour. Cutan. and Vener. Dis. 4:160, 1886.

32. Barnes, Edwin: Med. Rec. 1886, pp. 157-158.

33. Brown, A.: Med. and Surg. Reporter 54:762, 1886.

33" Rhus Diversiloba Remedy, Med. and Surg. Reporter 54:603, 1886.

34. Regensburger, A. E.: Treatment of Rhus Poisoning, J. Cutan. and Vener. Dis. 4:244. 1886.

35. Baldwin, A. E.: A Case of Poisoning by Rhus Toxicodendron, Pacific M. \& S. J. $30: 509-512,1887$.

36. Couch, L. B.: The Treatment of Rhus Poisoning, Med. Rec. 32:486; 1887 
year recommended frequent and thorough washing with hot soapsuds, and asserted that this treatment removed the irritant.

Hawley, ${ }^{37}$ in 1890 , stated that the use of oil of palustre ledum $3 x$ if administered when the eruption first appeared would cause all symptoms to disappear within forty-eight hours.

Aulde ${ }^{38}$ used whitewash externally in 1890 . Kite ${ }^{39}$ used black mercurial lotion similarly in 1891 . Other external applications recommended in 1891 were a decoction of chestnut leaves (Castanea fagus) by Straley, ${ }^{40}$ thymol iodid by Levick, ${ }^{41}$ concoction of fluid extract of serpentaria (Virginia snakeroot) Walker. ${ }^{42}$

In 1894, Cantrell ${ }^{\mathbf{4} 3}$ used full strength solution of chlorinated soda (Labarraque's solution) with good results in seven cases.

An anonymous author, ${ }^{44}$ in 1895 , recommended the juice or infusion of the touch-me-not (Impatiens fulva). Cantrell ${ }^{45}$ recommended phenyl salicylate (salol) and Labarraque's solution. Witmer ${ }^{48}$ in the same year published, as a topical application, lead water and opium, to be used during the acute stage with $1 / 2$ grain of mercuric chlorid internally, every three hours.

Brown $^{47}$ two years later (1897), considered a mixture of equal parts of lime water and linseed oil a good external application; and Clarke ${ }^{48}$ recommended a solution of borax. During the same year Smith ${ }^{49}$ recommended lime water as effective; Todd ${ }^{50}$ prescribed black mercurial lotion; Gilpin, fluid extract of serpentaria ; Cloyd ${ }^{51}$ the juice of the wild touch-me-not; Winfield, ${ }^{52}$ a paste of 0.5 to 1 per cent.

37. Hawley, J. W.: Rhus Poisoning, Med. Advance 24:257-262, 1890.

38. Aulde, John: Med. and Surg. Reporter 63:360-365, 1890.

39. Kite, J. A.: Weekly Med. Review 23:12, 1891.

40. Straley, S. B.: Weekly M. Review 23:166, 1891.

41. Levick, J. J.: Med. News 59:105, 1891.

42. Walker, J. B.: Poisoning by Ivy at Second Hand, Med. News 59:556, 1891.

43. Cantrell, J. A.: A Treatment for Ivy Poisoning, Phila. Polyclinic 3: $181-182,1894$.

44. An Antidote for Poison Ivy, Kansas M. J. 7:633, 1895.

45. Cantrell, J. A.: Phila. Polyclin. 4:99, 450, 1895.

46. Witmer, A. F.: Mercuric Chlorid in the Treatment of Rhus Poisoning, Phila. Polyclin. 4:267, 1895. 1897.

47. Brown, C. A.: Poisoning by Rhus Toxicodendron, Med. Brief 25:704,

48. Clarke, T. H.: Rhus Toxicodendron Poisoning, Med. Brief 25:1006, 1897.

49. Smith, C. D.: Med. Brief 25:1195, 1897.

50. Todd, J. D.: Rhus Toxicodendron Poisoning, Med. Brief 25:696, 1897.

51. Cloyd. A. D.: Med. Brief 25:916, 1897.

52. Winfield, J. M.: Brooklyn M. J. 11:404, 1897. 
ichthyol, with magnesium carbonate, olive oil and simple ointment; Bartley, ${ }^{53}$ sodium bicarbonate or lye water; and Hunt, ${ }^{54}$ red mercuric iodid.

Next year (1898), Frank ${ }^{55}$ prescribed baths followed by antiseptic emulsions containing calamin, glycerin, lime-water and the like.

In 1903, Klotz $^{56}$ used one part icthyol to three parts of water as an application for the inflamed area; Thudichum, ${ }^{57}$ three drops of tincture of rhus to two-thirds glass of water, a teaspoonful of the mixture to be taken three times daily, and boric acid to be used as a dusting powder. Thudichum said his daughter, having used lemon juice to remove freckles, tried it for poison ivy, and a cure resulted within thirty-six hours. Pollard ${ }^{58}$ used a decoction of California "buckbrush" leaves locally. Hughston ${ }^{59}$ (1905) applied with unvarying success lead acetate 10 grains, mixed with spirit of nitrous ether, 1 ounce.

In 1906, Daniel ${ }^{60}$ considered a mixture of quinin sulphate in water a specific, and it cured more rapidly than calomel, 16 grains mixed with 4 ounces of lime water. Milton ${ }^{61}$ believed immunity to rhus poisoning resulted from a few doses of European anacardium.

Lindley, ${ }^{62}$ in 1908 , recommended a solution of lead acetate and tincture of deodorized opium preferable to alcohol, hydrogen peroxid, boric acid and potassium permanganate. An anonymous writer ${ }^{63}$ used a calamin and lead lotion.

Ellis ${ }^{64}$ (1910) considered the best remedy sodium bicarbonate, when used as a dusting powder and covered with lime liniment. This he believed to be better than a saturated solution of sodium thiosulphate, a saturated solution of borax, a lead and opium wash, talcum powder, phenol ointment (1-30), iodin ointment, camphorated phenol ointment, lead acetate solution, zinc sulphate solution, and thymol iodid.

\section{RATIONAL REMEDIES}

Rational topical remedies are considered as based on general therapeutic principles and more or less erroneous conceptions of the chemical

53. Bartley, E. H.: Brooklyn M. J. 11:405, 1897.

54. Hunt, J. H.: Rhus Poisoning, Brooklyn M. J. 11:392-406, 1897.

55. Frank, L. F.: Med. Rec. 53:551-554, 1898.

56. Klotz, H. G.: Merck's Arch. 5:225, 1903.

57. Thudichum, C. L.: Rhus, Skookum Chuck, Alkaloidal Clinic 10:831-834, 1903.

58. Pollard, F.: Poison Oak, Alkaloidal Clinic 10:599, 1903.

59. Hughston, W. L. : Poison Ivy, Med. Brief 33:678-679, 1905.

60. Daniel, T. J.: A Specific for Rhus Poisoning, Med. World 24:299, 1806.

61. Milton, R. L.: Med. World 24:59-60, 1906.

62. Lindley, J. S.: Rhus Poisoning, Am. J. Dermat. 12:342-344, 1908.

63. British M. J. 11:545, 1910.

64. Ellis, Richard: Poison Ivy Rash, Med. Rec. 78:160-161, 1910 
nature of the poison and its pharmacologic action. The list of these remedies seems to begin with Horsfield ${ }^{1}$ in 1798 . Owing to the incomplete chemical analyses of Khittel, ${ }^{7}$ in 1857 , and Maisch, ${ }^{8}$ in 1865 , by which the poison was first considered a volatile alkaloid and then a volatile organic acid, more remedies were produced. Burrill, ${ }^{65}$ in 1882, believed the disease to be caused by a specific parasite that infests the rhus (a view supported by Hubbard ${ }^{66}$ in 1885 , and Frost, ${ }^{67}$ in 1916), and introduced disinfectants among the list. The work of Pfaff, ${ }^{68}$ in 1897, which resulted in the poison's being considered a nonvolatile oil, was the cause of still other remedies. Acree and Syme ${ }^{69}$ by their discovery, in 1906, of a supposed toxic glucosid of fisetin, rhamnose and gallic acid in $\mathrm{R}$. toxicodendron made further alterations in the list necessary. Despite the successive discoveries as to the nature and cause of rhus dermatitis, the list of remedies, instead of decreasing, increased with each successive experiment. There were physicians who until 1908 (two years after the work of Acree and Syme) still believed the active principle to be the toxicodendric acid of Maisch and others who insisted upon its being the toxicodendrol of Pfaff.

If those substances and methods which have been used to allay the pain, itching and systemic effects, as well as those that assist involution, are excluded the list of remedies is not nearly so long as those of the empiric or inductive type.

The first substance used in an attempt at rational treatment was mercuric chlorid. This was employed by Horsfield (1798) with the hope that by its corrosive action on the skin the poison would be thrown off the affected area.

The next attempt at rational treatment involved the employment of those chemicals which when added to the poison in laboratory glassware might be expected to produce nontoxic compounds. To my present knowledge, the first experimenter in this line was Maisch (1865). In this connection he says:

As remedies against it, I have tried subacetate of lead, permanganate of potassa and ammonia, the last, I believe, with the best success. Alkaline solutions were first recommended by Professor Procter, I believe, and, as my experi-

65. Burrill, T. J.: Some Vegetable Poisons, Am. Monthly Microscop. J. 3: 192-196, 1882.

66. Hubbard, S.: Rhus Toxicodendron, Peoria Med. Monthly 6:323-324. 1885-1886.

67. Frost, L. C.: Bacterial Etiology of Poison Oak Dermatitis (Rhus Poisoning), Med. Rec. 90:1121-1123, 1916.

68. Pfaff, Franz: On the Active Principle of Rhus Toxicodendron, J. Exper. Med. 2:181-196, 1897.

69. Acree, S. F., and Syme, W. A.: Some Constituents of the Poison Ivy Plant, Am. Chem. J. 36:301-321, 1906. 
ments show, they are the remedies which a priori might be expected to afford the greatest relief, just as in the case of formic acid. The eruption produced by this acid is very similar in its nature to the one produced by toxicodendric acid, and its effects yield readily to alkaline lotions. It is not unlikely that, like the formates, the toxicodendrates are without any ill effects, if applied externally. The reactions of our new acid show, likewise, the reason why permanganate of potassa, subacetate and even acetate of lead may be valuable remedies for this eruption. While the former completely decomposes it, the last named salts produce nearly insoluble precipitates with it; at least, toxicodendric appears to be stronger in its affinities than acetic acid.

Dr. James White, ${ }^{11}$, writing in 1873 and again in 1887, considered the poison to be the toxicodendric acid of Maisch. With this idea in mind, he says:

We have to deal with an acid, and the antidote for an acid is an alkali, that is, provided the salts thus formed are not equally poisonous. In poisoning by oxalic acid, for instance, potash is not an antidote, because the combination formed is nearly as poisonous as the acid itself. Whether the salts formed with toxicodendric acid by ammonia, potash, and soda are likewise poisonous, Professor Maisch leaves us somewhat in doubt as the result of experiment, but speaking clinically he leads us to believe that they are not; for he says that the application of solutions of ammonia seemed to be most effective in counteracting the action of the acid. This is consistent with the popular reputation of solutions of saleratus and soda as remedies, and will explain the action of the soft-soap. These are true antidotes, but they can be of benefit only from their chemical action, and in this way.

Of the other writers who believed the poison to be the volatile toxicodendric acid of Maisch, Park, ${ }^{70}$ in 1879, recommended the use of a camphor-chloral mixture (equal parts of each allowed to stand in the open air and liquefy); Brandt, ${ }^{11}$ in the same year, used a saturated solution of sodium thiosulphate, externally and internally, and aborted the worst cases in from twenty-four to forty-eight hours. He also used alkaline bicarbonates and lime water locally and internally with "fair success," Ward ${ }^{72}$ (1879) prescribed Labarraque's solution, concentrated when the skin was unbroken and diluted with from three to six parts of water when the skin surface was broken. Johnson ${ }^{73}$ (1886) used externally a formula of sodium thiosulphate, 1 ounce, distilled water 8 ounces, phenol, 1.5 drams, glycerin, $1 / 2$ ounce. Internally he used potassium iodid, 2 drams, distilled water, 7 ounces, syrup, 1 ounce, a tablespoonful four times a day. Beringer ${ }^{\text {t }}$ (1896) used granular

70. Park, R.: Dermatitis Venenata-or Rhus Toxicodendron and Its Action, Arch. Dermat. 5:227-234, 1879.

71. Brandt, W. E.: Poisoning by Rhus Radicans, Med. Rec. 16:46-47, 1879.

72. Ward, J. M.: Poisoning by Rhus Radicans, Med. Rec. 16:117, 1879.

73. Johnson, J. B.: Med. and Surg. Reporter 54:508, 1886.

74. Beringer, G. M.: Rhus Poisoning, Am. J. Pharm. 68:18-20, 1896. 
sodium thiosulphate $1 \mathrm{dram}$, glycerin, $1 / 2$ fluidounce, camphor water, sufficient to make 4 fluidounces; also he used hot soda baths, and as a preventive treatment washing the face and hands with a solution of hydrogen peroxid. Davis ${ }^{\text {is }}$ (1897) considered as a remedy a warm bath for from 15 to 20 minutes at blood heat to which 4 ounces of borax had been added. The cuticle was dried and cosmolin applied. In one hour a strong solution of lead acetate, a weak ammonia water, sodium carbonate, alum curd, or a tincture of Grindelia squarrosa (?) was applied. Hadden ${ }^{76}$ prescribed, in 1906, Labarraque's solution as better than alcoholic lead acetate; Conner ${ }^{i 7}$. (1907) used sodium thiosulphate mixed with glycerin and phenol, or a solution of benzoic acid and solution of formaldehyd with an equal amount of saturated solution of sodium thiosulphate. He considered quinin solution of little value; and Ward ${ }^{78}$ (1908) used as a lotion a saturated solution of aluminum acetate, or if this is not to be had, he used phenol from 2 to 4 per cent., sodium bicarbonate, sodium sulphite, lead acetate, lotion of lead and opium or black mercurial lotion.

When the poison was found to be a nonvolatile oil by Pfaff (1897), a modified method of treatment was prescribed. He recommended the precipitation of the poison with lead acetate, copper or iron. Ordinary oxidation, he says, is very slow, but may be slightly accelerated by a solution of sodium carbonate. He does not recommend the use of oxidizers, however.

Of the physicians who followed the discovery of Pfaff, Schwalbe, ${ }^{79}$ in 1903, recommended the use of alkalies to destroy (saponify?) the oil; he accordingly prescribed a 0.1 to 0.5 per cent. solution of potassium carbonate or a 1 to 1.5 per cent. solution of ammonium chlorid. McKee $^{80}$ (1906) believed a formula consisting of alcohol 53 per cent., distilled water, 47 per cent., and lead acetate, sufficient to make a saturated solution, would give relief for from six to eight hours. Guernsey $^{81}$ (1913) considered' a saturated solution of magnesium sulphate best, although he also recommended the use of strong soap and water to "neutralize the acidity of the oil," a 50 per cent. alcohol solu-

75. Davis, W. T.: Rhus Toxicodendron Poisoning, Med. Brief 25:938-940, 1897.

76. Hadden, A.: Poison Ivy or Rhus Toxicodendron, Med. Rev. of Rev. 12:764-765, 1906.

77. Conner, J. J.: Poisoning by Rhus Toxicodendron, Am. J. Dermatology 11:368, 1907 .

78. Ward, R. F.: Severe Ivy Poisoning, New York M. J. 88:1224-1225, 1908.

79. Schwalbe, C.: On the Active Principle of Rhus Diversiloba (Poison Oak), Med. Rec. 63:855-856, 1903.

80. McKee, E. S.: Poisoning by Rhus Toxicodendron or Rhus Radicans, Med. Herald, N. S. 25:98-100, 1906.

81. Guernsey, J. C.: Rhus Poisoning, Hahneman. Month. 48:161-174, 1913. 
tion of lead acetate, from 2 to 4 per cent. potassium permanganate, 1.5 per cent. ammonium chlorid, hydrogen peroxid, 1 teaspoonful of sodium carbonate to a quart of water, sodium thiosulphate, 1 part of household ammonia to 2 parts of water, a solution of alum, and thymol iodid or alum dusting powder.

Syme (1906) considered the poison a glucosid of rhamnose, fisetin and gallic acid. In counterdistinction to Pfaff, he recommended the use of an oxidizer, namely potassium permanganate. Syme said in part:

The best example of the latter was obtained with the ether solution from the extraction of the lead precipitate in the Soxhlet apparatus. After removing the ether, a small drop of the residue was applied to the wrist as described. An itching red spot about the size of a dime was noticed in thirty-six hours, and it steadily increased in size. Nearly two days after the application of the poison, a dilute solution of potassium permanganate containing a little caustic potash was rubbed into the spot until the pimples were destroyed. A little black spot was left wherever there had been a pimple, showing that the permanganate had been reduced to oxid in the skin. The place was washed and nothing more was thought of it until the norning following, when it was noticed that the wrist had commenced to swell during the night, and the characteristic watery secretion was running from the poisoned spot. More permanganate solution was applied without potash and the wrist was bandaged, thinking that this would prevent the spreading of the eruption, but it really facilitated spreading by becoming saturated with the poisonous fluid and keeping it in contact with a larger surface of skin. In the meantime the swelling and.inflammation had extended nearly to the elbow. The arm now had the appearance of having been bitten by a snake. To reduce the swelling it was immersed in hot water. This seemed to bring out the eruption very quickly and the blisters were treated with permanganate as fast as they appeared. The swelling was reduced, but returned during the night. On the evening following, the forearm was immersed in a bowl of hot permanganate solution containing a little caustic potash. The solution was kept as hot as could be borne for about half an hour. After this bath, the poison was completely oxidized, for the swelling was reduced and did not return, nor was there any fresh eruption. What appeared to be a severe case of poisoning was thus cured very quickly. The use of hot water not only reduces the swelling, but also helps to destroy the poison. The action of permanganate is also more rapid at high temperatures.

The oxidizing power of permanganate, as is well known, is greater in acid solution than in alkaline, five atoms of oxygen being available in the former and three in the latter, according to these equations:

$$
\begin{aligned}
& 2 \mathrm{KMnO}_{4}+3 \mathrm{H}_{2} \mathrm{SO}_{4}=\mathrm{K}_{2} \mathrm{SO}_{4}+2 \mathrm{MnSO}_{4}+3 \mathrm{H}_{2} \mathrm{O}+50 . \\
& 2 \mathrm{KMnO}_{4}+\mathrm{H}_{2} \mathrm{O}=2 \mathrm{MnO}_{2}+2 \mathrm{KOH}+30 .
\end{aligned}
$$

Permanganate was used as a remedy in some cases mixed with dilute sulphuric acid, and in others, with zinc sulphate; also with lime water. It was found to be satisfactory whether used alone or with any of the substances mentioned, provided it was well rubbed into the skin. The concentration of the solution used was varied according to the location and condition of the eruption. Where the skin was thin or already broken, dilute solutions (1 per cent.) were used. In one case, the eruption appeared in the palm of the hand 
where the skin was so thick that it was necessary to open it before the remedies could reach the poison. The difficulty of getting the remedy in contact with the poison in the skin is the reason why the eruption is hard to cure.

Syme also opposed the use of an alcoholic solution of lead acetate as a remedy:

This remedy is unsatisfactory for the reason that its action consists in depositing an unstable lead compound of the poison in the skin where the conditions of moisture and temperature are favorable for its decomposition, liberating the poison with all its irritant properties. Moreover, alcoholic preparations should not be used because the alcohol dissolves the poison and, on evaporation, lets it spread over a larger surface like a varnish. Potassium permanganate, however, oxidizes the poison completely. The only objection to the use of permanganate of which the writer is aware is that it stains the skin. The stain can be removed by vigorous scrubbing with soap, or it will wear off gradually in a few days. It can be removed at once by certain acids, but these should not be used by persons not familiar with their action.

Dr. Baird ${ }^{82}$ on the strength of this knowledge recommended a 2 to 4 per cent. solution of permanganate in 1909.

According to my present knowledge, the next person who attempted to find an antidote through a search for a chemical neutralizer was Dr. von Adelung, ${ }^{83}$ in 1912 . He believed the poison to be the glucoside of Acree and Syme. His experiments in that line were as follows:

Experiment 14.-Ammonia water.-Equal parts of ammonia and tincture of rhus were mixed and tested on the skin. The mixture is toxic, from which it is evident that ammonia does not destroy the poison.

Experiment 15.--Peroxid of hydrogen.-Because it is a strong oxidizer, it was presumed that hydrogen peroxid would have some curative property. But when tested by adding it in equal quantity to the rhus tincture, it failed to inhibit the toxicity, and when tested, with control, on a patch of dermatitis it was found inert.

Experiment 16.-(Aristol.)-The left of two artificial patches of dermatitis was treated during five days with a solution of aristol in cotton-seed oil. The control received no treatment. Both were scratched. Result: The untreated patch recovered first.

Experiment 17.-The same test was made on the left of two spots produced by green leaves. The aristol in oil was applied five times in four days and protected by gatue held in place by plaster. Result: No difference could be noted. Aristol therefore appears to be of no value.

Experiment 18.-(Castor Oil.)-A mixture of equal parts of 10 per cent. tincture of rhus and castor oil was rubbed on the arm. In thirty-six hours there was a slight itching, but no eruption.

Experiment 19.-(Cedar Oil.) - A similar mixture with cedar oil was applied to the arm. After thirty-six hours, a slight eruption appeared which later developed into a fair patch of itching dermatitis.

82. Baird, A. W.: Ivy Poisoning, Med. Rec. 76:232, 1909.

83. Von Adelung, Edward: An Experimental Study of Poison Oak, Arch. Int. Med. 11:148-164, 1913. 
Experiment 20.-(Cottonseed Oil.)-A similar mixture with cottonseed oil was applied to the thin skin of the wrist. After eight days no dermatitis had appeared.

Experiment 21.-Cottonseed oil in which green leaves had been soaked for twenty-four hours was applied to the arm. The result was slight dermatitis. This, repeated on another person, gave the same result.

Experiment 22.-Some cottonseed oil in which green leaves had been heated was applied to the arm. After four days, itching began, and in five days, a slight eruption.

Experiment 23.-A mixture of equal parts of tincture of rhus and cottonseed oil was applied to the arm. No dermatitis was detected in eight days.

These results raised the question whether cottonseed oil did not combine chemically with the toxin, destroying the toxicity. To test this point, the mixture of oil and tincture was allowed to stand a few days, when the tincture formed a layer above the oil. This supernatant fluid was toxic, producing dermatitis.

Experiment 24.-A mixture of equal parts of tincture rhus and of tincture of green soap was applied to the arm and protected by gauze. After twenty-four hours only a slight eruption was noted.

Experiment 25.-A mixture of tincture of rhus, 25 parts, and tincture of green soap, 5 parts was applied to arm and protected with gauze. Only slight dermatitis resulted.

Experiment 26.-After allowing tincture of green soap to dry on a spot, tincture of rhus was applied. A control spot was made with the rhus alone. Both spots were protected with gauze. The control took well, while the soaped spot showed a slight dermatitis. Thus it appears that soap deters the poison of rhus.

Experiment 27.-(Ichthyol Collodion.)-The worse of two patches of dermatitis, three days old, was painted with a 5 per cent. ichthyol collodion daily. In twenty-four hours, distinct improvement was noted in the treated patch, and this patch recovered earlier. This was confirmed in treating hospital cases.

Experiment 28.-(Hyposulphite of Sodium.)-Tests with this substance were also negative. It failed to inhibit the toxicity when added in large proportion to the tincture of rhus; and it failed to show curative effect on dermatitis patches compared with controls.

Experiment 29.-(Iodid of Potassium.)-This substance in strong solution, added to an equal part of tincture rhus, failed to inhibit the toxicity as tested on the skin.

Experiment 30-(Tincture of Iodin.) - Full official strength tincture of iodin when mixed with an equal quantity of tincture of rhus destroys the poison; for when this mixture is tested on my arm no dermatitis results. If, however, the strength is reduced to less than 5 per cent. of the mixture, by addition of water or alcohol, the toxicity is not destroyed completely.

Experiment 31.--Tincture of iodin also has curative property. To one of two patches of dermatitis, official tincture of iodin was applied. The application burned. But the treated patch recovered earlier than the control. Itching quickly subsided and healing followed. The spot remained discolored and tender, presumably from iodin burning.

Experiment 32.-The right of two patches of dermatitis was rubbed with 90 drops of water mixed with 10 drops of tincture of iodin. The control was rubbed with alcohol. The application of iodin caused a burning sensation, not 
severe. In twenty-four hours the rhus dermatitis had disappeared, but was replaced by an iodin burn. The control ran a normal course.

Experiment 33--(Potassium Permanganate.) - A mixture of equal parts of potassium permanganate $(0.56 \mathrm{gm}$. in $120 \mathrm{c.c}$. $)$ with tincture rhus, when tested on the arm was found to be absolutely nontoxic.

Experiment 34.-One of two patches of dermatitis was painted with potassium permanganate in the above strength. The treated patch healed earlier than the control.

Experiment 35.-(Magnesium Sulphate.)-Chemical Tests: A fresh rhus leaf macerated with a saturated solution of magnesium sulphate remained toxic, as proven by testing on my arm.

Experiment 36.-Saturated solution of magnesium sulphate (Squibb's), added in equal quantity to tincture rhus, does not inhibit the toxicity, for dermatitis results when the mixture is applied to the skin.

Making use of the solubility of rhus poison, therapeutic experiments have been based on the remedial value of solvents as well as chemical agents. Maisch and White considered the poison soluble in water and recommended that parts exposed to rhus be immediately washed or bathed for a considerable time in water. Pfaff prescribed the mechanical removal of the poison as soon as possible after exposure by vigorously washing the affected and exposed parts with soap, water and a scrubbing brush. As the poison is soluble in alcohol, Pfaff likewise believed in thoroughly washing with alcohol and a scrubbing brush, or in washing the exposed parts with an alcoholic solution of lead acetate. $\mathrm{He}$ also recommended the use of oils, including petrolatum, if quickly removed and repeatedly used so as not to spread the poison. Syme, as previously quoted, believed the poison would be spread by the use of alcoholic lead acetate. Stevens ${ }^{84}$ (1906) obtained the best results by rubbing the surface with a little petrolatum, which he scraped off with a knife, and washing the surface with a weak solution of sodium hydroxid or carbonate. He also recommended alcohol, petroleum benzin, ether or kerosene as washes to remove the poison. As heretofore quoted, von Adelung experimented with castor, cedar and cottonseed oils.

In the belief that the poison was Pfaff's toxicodendrol, Balch ${ }^{85}$ (1906) said :

The use of soap and water and a good hand brush is the simplest method of getting rid of the oil. The action is entirely mechanical and is perfectly efficient. Alcohol dissolves and removes the oil, but successive portions must be allowed to flow over the part as after contact the alcohol may contain sufficient oil to spread the irritation. Ordinary alcohol must be used and not 50 per cent. alcohol as the latter does not dissolve the oil. The action is purely a solvent one and not one of neutralization. 1906.

84. Stevens, A. B.: Japanese Lac, Inaugural Dissertation, Ann Arbor, Mich.,

85. Balch, A. W.: Poison Ivy, J. A. M. A. 46:819-820, 1906. 
Guernsey (1913), also a follower of Pfaff, recommended the use of a wash of alcohol, whisky or ether to remove the poison.

Many physicians have made clinical comparisons of various popular remedies, with or without taking into consideration the chemistry of the poison. Such comparisons of remedies, which were made successively on the same patient and therefore in different stages of the disease, are considered.untrustworthy and are therefore eliminated. The earliest of these comparisons is that of Dr. Bigelow ${ }^{12}$ (1820). He says:

The acetate of lead is perhaps as useful as any external palliative, and it should be used in solution rather than in the ointment, that it may be applied as cold as possible. The late Dr. Barton speaks highly of a solution of corrosive sublimate externally applied in this disease, but from trials of the two remedies made at the same time and in the same patient, I have found the lead the more beneficial of the two.

Cantrell ${ }^{86}$ (1898), who carried his experiments over a long period of time and who had an abundant opportunity for experimental work, summed up the relative values of certain drugs in the treatment of ivy poisoning in order of preference, as follows: First, Labarraque's solution (dilute in erythematous and concentrated in vesicular); second, phenyl salicylate (salol) 0.5 dram to the ounce of petrolatum liquefied or ether, because both produce a cure in less than a week's time; third, bromin (10 grains to the ounce of some oily substance) cures in about ten days; fourth, boric acid (saturated or dilute solution) cures in about two weeks; fifth, acetanilid ( $1 / 2$ dram to 1 dram to the ounce of liquid petrolatum) cures in about two or three weeks, because they may be relied on to produce no ill effects; sixth, Grindelia robusta (fluid extract 2 drams to the pint of water, more concentrated irritates), cures in about two weeks. This can always be relied on to produce a cure, but it is long delayed and may if not watched carefully produce a higher grade of inflammation.

Von Adelung in 1912 carried on comparative therapeutic tests as follows :

Though magnesium sulphate fails to destroy the toxicity of rhus when mixed with its tincture, or its juice, it, nevertheless, possesses definite therapeutic value.

Experiment 37.-Test 1: In one of two patches of dermatitis, saturated solution of magnesium sulphate was rubbed three times at hour intervals. By the next morning the treated patch was better than the control. Three more similar applications were made during the forenoon and by noon a very marked improvement was noted. The treated patch recovered earlier than the control.

86. Cantrell, J. A.: Relative Value of Certain Drugs in the Treatment of Ivy Poisoning, New England M. Monthly 17:270-272, 1898. 
Test 2.-To one of two patches of dermatitis, saturated solution of magnesium sulphate (Squibb's) was applied on gauze, covered with rubber tissue, and a bandage. A similar dressing was applied to the control, using water in place of magnesium. After twenty-four hours, while the first patch was not healed, it was free from itching, was not tender, and not edematous, thus contrasting with the control, which remained tender for six days.

\section{HOSPITAL CASES}

A. B., male, aged 23 , was poisoned four days previously. Whole face was edematous and the right eye closed. On Oct. 25, 1911, in the afternoon, hot applications of 2 per cent. permanganate were begun, but applied only to the right side of the face. In thirty hours the right eye was in good condition. The left side recovered tardily.

B. C., male, March, 1912, face and hands severely poisoned. The right side of the face and the right arm were treated with the hot permanganate, while the opposite side was treated with hot standard photographer's solution of sodium hyposulphite. In addition, both arms were bandaged in their respective solutions. After twenty-four hours the patient stated that the permanganate side felt distinctly better than the other. The right side recovered the earlier.

E. U., male, aged 25, was poisoned four days previously. Both arms showed marked edema, vesicles and pustules. He had already applied cold permanganate six or seven times. Hot permanganate was applied frequently by the nurse. There was no improvement in forty-eight hours. When the solution was changed to hot mercuric chlorid, and bandaging begun with the same, recovery began.

This case illustrates the uselessness of permanganate when the vesicles become infected.

A. E., male, aged 45. Dermatitis one day old. The whole face was swollen. The eyes half closed by edema of both lids. The right ear was much swollen. Thirty hours after the dermatitis began, hot permanganate saturated solution was applied to all areas. The application burned severely, especially the eyelids. Recovery occurred in five days, though this man had always been two weeks getting well. A weaker solution of permanganate would have been better.

Besides the results of Bigelow, Cantrell and von Adelung little can be attempted in summarizing the comparative values of these remedies as the results obtained by different physicians with the same remedy are so often conflicting.

One of the chief reasons for this unsatisfactory condition is the fact that many physicians in treating a case of rhus dermatitis will first use a so-called remedy for a few applications; failing to secure a satisfactory result this remedy will be replaced by another. This process may continue until finally convalescence, delayed or accelerated by the use of the various remedies, occurs and the remedy used in the last stages of the disease is considered the best. This remedy may then be used by another physician or the same physician in the initial stages of another case with failure as a result. A condition of disputation and uncertainty 
results. In support of this explanation there are the published cases of Bartlett $^{87}$ (1838), French ${ }^{88}$ (1903), Matheson ${ }^{89}$ (1874), Morris ${ }^{90}$ (1897), and Stone ${ }^{91}$ (1874).

A further discussion of remedies will be taken up in a paper on the chemotherapy of rhus dermatitis.

87. Bartlett, E.: Use of Chloride of Soda in Cases of Poisoning with Rhus Radicans, Boston M. \& S. J. 18:303, 1838.

88. French, J. M.: Rhus Toxicodendron and Rhus Poisoning, Merck's Arch. 5:223-225, 359, 1903 .

89. Matheson, A. C.: Treatment of Poisoning by Rhus Toxicodendron with Linseed Oil and Lime Water, Am. J. M. Sc., N. S. 67:118, 1874.

90. Morris, E. K.: Guaiacol in Rhus Poisoning, Med. News 70:57, 1897.

91. Stone, I. S.: Poisoning by Rhus Toxicodendron, Am. J. M. Sc., N. S. $67: 569,1874$.

\section{CORRECTION}

In the article by Dr. Robert S. Hodges on "Ringworm of the Nails," which appeared on page 1 of the July issue, on page 25, line 4 should read "attacking the nails." 